\title{
Framing emotions in early childhood teaching within Deleuze's concept of sense: Intensity and significance
}

Alison Warren, Te Rito Maioha Early Childhood New Zealand, Nelson, New Zealand. e-mail alison.warren@ecnz.ac.nz

\begin{abstract}
Within posthumanist perspectives that draw on Deleuze's concept of sense, emotions are reconceptualised as localised and complex processes that respond to affective flows within networks of relationships. Opportunities are opened for critical and creative engagements within early childhood teaching that challenge perceptions of teachers' responsibilities for experiencing, expressing, and managing 'their' emotions as self-contained individuals. Emotions are framed as complex, nuanced, pre-individual, and impersonal processes of sensing intensity and significance. Following Deleuze, sense is understood to be sensed as changes in intensities among verb infinitives that express 'what is going on' in a localised situation. Data from a research study into emotions in early childhood teaching is analysed using a concept-as-method mapping approach that draws on Deleuzian concepts of sense, nonsense, paradox, and problem. Teachers and researchers are challenged to consider themselves as dynamic, always-emerging, individuating processes and relationships rather than pre-existing knowing individuals containing emotions as distinct entities.
\end{abstract}

Keywords: Deleuze, sense, childhood teaching emotions, early

\section{Introduction}

This article argues that Deleuze's (1969/1990) concept of sense can be used productively to reconceptualise emotions and complexify what emotions do in early childhood teaching, opening opportunities for creative political engagement within early childhood teaching. Within posthumanist perspectives, bodies, matter, thoughts, and emotions are produced 
Framing emotions in early childhood teaching within Deleuze's concept of sense: ... 22

within pre-individual and pre-personal relationalities and processes rather than being produced by pre-existing human individuals who think, know, and act autonomously. Methodological opportunities arise when posthumanist perspectives and Deleuzian concepts encounter data from a research study in Aotearoa New Zealand investigating emotions in early childhood teaching (Warren, 2019). A teacher, Mila (pseudonym), and a group of three to four-year-old children were observed and video-recorded engaging in an everyday routine of applying sunscreen after lunch before playing outside at an early childhood centre. Mila and I discussed the video-recording and our recollections, thoughts, and emotions during a research conversation. Data were generated from video-recordings, field notes, and conversation transcripts. I developed a vignette from these data and chose a series of Mila's statements from our conversation for analysis.

An account is given of a cartographic analysis of the vignette using Deleuze's concept of sense as well as associated concepts such as nonsense, paradox, and problem. Emotions are reconceptualised within this conceptual framework and within posthumanist perspectives. I move away from assumptions that emotions are contained within human individual teachers who are responsible for how 'their' emotions are experienced and expressed. Instead, emotions are understood as localised and complex processes that respond to affect that flows within networks of relationships. The localised and nuanced nature of networked and emergent emotions is explored through attention on intense relations among significant verb infinitives that express 'what is going on' without attachment to particular human individuals. Verb infinitives such as 'to care' or 'to follow health and safety policies' partially express what is going on in the data excerpt discussed in this article. Taking this theoretical analytical approach may reveal cracks and fractures in taken-for-granted assumptions about what emotions can and should do in early childhood teaching, releasing opportunities for critical, localised, political engagement through creativity and innovation.

Taken-for-granted humanist perceptions of emotions in early childhood teaching as contained within individual teachers are entangled with understandings of care, love, and professionalism. Idealised understandings relate teachers' caring words and behaviours to emotions such as love, warmth, trust, joy, and empathy. However, early childhood teachers engage in emotional labour to express a range of acceptable emotions (Colley, 2006; Vincent \& Braun, 2013). Concerns and anxieties surrounding caring and loving relationships are entangled with discourses of risk and danger that position children as passive, innocent, and vulnerable and adults as potentially dangerous (for example, Page, 2018). Tensions exist between how emotionality that underpins warm, caring, and trusting relationships in early childhood settings is valued, and how rationality is valued as more professional than emotionality. Such tensions are evident in examples such as the removal of 'care' from official teacher education documentation in Norway (Aslanian, 2018) and the emphasis on rationality and accountability in government discourses of early childhood quality in the United Kingdom (Osgood, 2010), rather than placing value on emotional and relational capacities of teachers. In her research into the experiences of United Kingdom nursery workers, Osgood (2012) describes her participants as emotional professionals who understand and skilfully manage 
Framing emotions in early childhood teaching within Deleuze's concept of sense: ... 23

complexities of emotions while embedded in a neoliberal professional framework which devalues emotional professionalism.

This article will proceed by discussing theoretical and methodological frameworks of the research study, followed by an account of cartographic analysis that maps emergence of sense, nonsense, paradox, and problems from data. The article concludes with consideration of implications for early childhood teaching.

\section{Theoretical framework}

Deleuzian concepts of sense, nonsense, paradox, and problem are used to reframe emotions, teachers, and teaching within posthumanist perspectives. Sense is a "non-representing, unrepresentable, 'wild element' in language" (MacLure, 2013a, p. 658) that holds potential for innovative ways of thinking about emotions. Sense is produced and expressed as an incorporeal effect at the frontier between language and things, sensed as intensity and significance (Deleuze, 1969/1990). Sense is "what happens at the point at which language and the world meet. It is the happening, the event that arises when a particular proposition comes in contact with the world" (May, 2005, p. 100). Emotions framed within the concept of sense are understood as pre-personal, complex, and nuanced processes, rather than possessions of human individuals who might describe themselves as (for example) joyful, anxious, frustrated, or angry.

Deleuze and Guattari (1980/1987) prioritise relationality and continuous becoming over bounded, static forms, and structures: "There are only relations of movement and rest, speed and slowness between unformed elements, or at least between elements that are relatively unformed, molecules and particles of all kinds" (pp. 293-294). Rather than seeking to define what things are, Deleuze and Guattari are interested in how they work, their interconnections and intensive capacities. Understanding emotions as processes rather than entities shifts perceptions: "if something (e.g. an emotion) is a process not a substance, then it is not defined as a stable essence with the same mode of activity wherever it features" (Tucker, 2012, p. 772). Words used to describe emotions such as happy, sad, angry, or anxious are insufficiently nuanced to articulate dynamic and complex emotional experiences in specific early childhood teaching situations. Emotional complexities arise and are difficult to articulate; for example, when teachers experience tension between their commitment to warm and sensitive relationships and logistics of working conditions, emotionally draining work, and lack of management support (Page \& Elfer, 2013).

Immanence is an overarching concept in Deleuze and Guattari's (1980/1987) ontology that is important to this theoretical framing of emotions. The concept of immanence shapes understanding that everything exists on the same plane of reality; everything is always already in existence. Language, ideas, emotions, bodies, and states of affairs all exist on the same ontological plane. For teachers and researchers, immanence implies entangled immersion: "we are our situations, we are our moving through them, we are our participation - not some abstract entity that is somehow outside looking in at it all" (Massumi, 2015, p. 14). Teachers and researchers are not detached observers but are produced within the teaching or research 
situation. Thinking within immanence is not concerned with making meaning by categorising, interpreting, and representing what has come to be. Language that is immanent does not have a privileged role of transparently naming and interpreting things but emerges alongside everything else (including human, other-than-human, material, ideas, and emotions). This raises analytic possibilities to explore what else language can do within such immanent entanglements, besides denoting, describing, and explaining.

Emotions emerge immanently in networks of relational processes, partially articulated in language and partially experienced and expressed in changes in bodies. Registrations of affect may produce bodily changes in (for example) skin temperature and muscle tension. In the realm of language, emotions are verbalised through words that name, describe, explain, and express emotions. Some aspects of emotions elude both these ways of expression by being sensed but difficult to articulate. At the frontier where bodies and language articulate, emotions may be sensed in indistinct ways and expressed through inarticulate vocalisations such as laughter, crying, shouts of joy or rage, and feeling lost for words or overcome with emotion.

The concept of intensity produces understandings of what sense can do and how sense is sensed. Sense is described as variations in intensities in verb infinitives that register 'what is going on' in a situation without linking the event to particular individuals (Deleuze, 1969/1990; Williams, 2008). Intensity can be described as excitations, pure difference, and difference in itself. It shocks an unconscious sensibility which is receptive to intensities as flashes of pure difference but not perceptive of what is sensed (Hughes, 2009, p. 149).

In their research with early childhood teachers, Cumming and Sumsion (2014) describe participants' difficulty in articulating aspects of their work: "the sense that there is 'something' at work, but uncertainty as to what exactly it is" (p. 372). In Masny's (2016) research in a Canadian early childhood setting, she reads an encounter with a child's apparently inconsistent perception of language using concepts of sense, paradox, and nonsense. For Olsson (2009) in her research in Swedish early childhood settings, children's learning is open-ended and keeps moving through ongoing production of sense and nonsense, construction of problems and 'magic moments' rather than seeking solutions that are endpoints of learning.

\section{Methodology}

The research methodology is described as postqualitative and concept-as-method.

Postqualitative research departs from 'traditional' qualitative research by avoiding recipe-like methods and focusing on what is becoming (different from before) in localised experimentation (St. Pierre, 2019). Each postqualitative inquiry is different, responding to its own unique events as researchers encounter something that forces them to think (Deleuze, 1968/1994). Postqualitative researchers use contingent moves that respond to surrounding forces, like a spider weaving its web "in a space of emergent, fragmented strategies that mutate according to the task at hand" (Jackson, 2017). Expectations of validity of research do not fit within posthumanist ontology of reality and knowledge as continuously produced in entangled relationalities. Postqualitative research cannot be repeated as it is produced by 
"different contingent and unpredictable forces" (St. Pierre, 2019). Researchers, participants, data, theory, and analysis constantly intermingle in unpredictable ways (MacLure, 2013b; Sellers, 2013).

Concept-as-method is a methodological approach to postqualitative inquiry underpinned by Deleuze and Guattari's (1991/1994) belief that theory is practice rather than separated from practice, and the task of philosophy is creating concepts to think with, to create and innovate: "To think is to experiment, but experimentation is always that which is coming about - the new, remarkable, and interesting that replace the appearance of truth and are more demanding than it is" (Deleuze \& Guattari, 1991/1994, p. 75). A concept can provide a means to reorient thought (St. Pierre, 2019) and comes associated with other concepts that researchers can use to frame and reconceptualise their research situation. Reading about sense (Deleuze, 1969/1990) led me to associated concepts of nonsense, paradox, and problem. I began to think differently about emotions and what they do in early childhood teaching. Drawing on interconnected concepts in new ways that reorient our thinking may help escape the taken-for-granted: "we must preserve the right to a diverse repertoire of concepts for thought, and the room to experiment with diverse becomings that such a repertoire allows" (Krejsler, 2016, p. 1477).

Cartography is used in my research to map relations using some associated concepts from Deleuze's writing in encounter with data rendered as a vignette created from multiple data sources and some statements from early childhood teacher Mila. Cartographies are critical and creative, and helpful to researchers attempting to work with concepts in a new way, grasping new understandings and navigating relationships among concepts, and among concepts in relation with data: "critical cartographies ... assist us in the process of learning to think differently about ourselves, in response to the complexity of our times" (Braidotti, 2019, p. 4). Working in the Aotearoa New Zealand context, Sellers (2013) uses 'rhizomapping' to explore affective flows in which children and curriculum constitute each other performatively. Rhizoanalysis is a cartographic approach based in Deleuze and Guattari's (1980/1987) assemblage theory, and concurrently maps affective flows and traces the forces that constrain these flows (Lenz Taguchi, 2016).

The vignette used in this article was developed from multiple data: a video-recording, written observations, feelings, and memories associated with the observation, and transcripts of research conversations. The process of creating a vignette is selective as researchers read data intensively for affect, "moments of intensity in which the capacity of a body (human or otherthan-human) to act is changed" (Cumming, 2015, p. 57). MacLure (2013a) describes 'glowing' data as registering the emergence of sense, calling up "the double-sided, material-linguistic status of sense, 'resonating in the body as well as the brain'" (p. 661). Researchers are understood to be embedded and embodied interconnected relationalities (Braidotti, 2019) perceiving, expressing, and making decisions produced by forces, desires, and intensities of assemblages rather than self-contained individuals (Mazzei, 2013).

\section{Cartography of sense: Thinking with philosophical concepts}


This section explores a concept-as-method cartography process that maps relations among data and concepts of sense, nonsense, paradox, and problem. Theory and research practices shape each other in tangled networks of mapping processes that move from data to concepts to literature to thoughts and memories and back again. Cartographic analytic moves continue to produce me as researcher within iterative processes of observing, watching videoclips, talking with Mila, listening to audio-recordings of our conversations, reading transcripts, reading literature, writing my understandings of concepts, drawing diagrams, and writing analyses.

\section{Vignette: Mila, children, and sunscreen routine}

After lunch on a warm summer afternoon, Mila sits on the floor of the early childhood centre with a bottle of sunscreen, her back against the end of a shelving unit. Children line up in front of her, waiting to go outside to play once they have sunscreen applied. Mila usually takes responsibility for this routine, as her colleagues dislike doing it. Although Mila doesn't like how much time it takes, she's happy to step up when nobody else wants to do it. Sunscreen application is required for health and safety and it gives Mila an opportunity to have contact with each child. When Mila started teaching in this setting, the children strongly disliked having sunscreen applied. They responded well to Mila's playful, fun approach as she introduced the sunscreen bottle as 'Sunny the sunscreen', 'here to keep you safe from the sun'.

As each child approaches Mila, she takes some sunscreen in her hands, and rubs it into the child's arms. Then she gently applies sunscreen to the child's face in circular movements of her fingers and palms. Mila and four-year-old Tessa (pseudonym) talk about Tessa's dancing as Mila gently rubs sunscreen onto her arms and face. Tessa's face has an animated, happy expression and Mila's face is calmly attentive. Mila puts her finger on the pump of the sunscreen bottle. Tessa brings one hand up to the nozzle and presses her other hand on top of Mila's hand. Together they squirt some sunscreen into Tessa's hand, and she goes to touch her face with it. Mila smiles and reaches out her hand, reminding Tessa that her face already has sunscreen and that she should rub her sunscreen onto her legs.

This vignette tells a particular, localised story of care, responsibility, and compliance in early childhood teaching. Emotions are understood as complex, networked processes produced and registered in language and in bodies, and also as sense on the frontier of language and things. Sense is sensed in data that glow with affective intensity: "The glow seems to invoke something abstract or intangible that exceeds propositional meaning, but also has a decidedly embodied aspect" (MacLure, 2013a, p. 660). For example, there is something evocative, sensed but intangible in the combination of the sensual experiences of warmth, chatter, smells, and the smooth, cool feeling of the hard floor. In the vignette, sense is sensed in intensities on the frontier between language and states of affairs (including bodies). Language describes Mila sitting on the floor applying sunscreen to children lined up in front of her, language is present as conversation among Mila and the children, and the language of our research conversation about this occasion. The states of affairs include the bodies and 
materials of the early childhood centre: warmth of the sunny afternoon, smells of lunchtime and sunscreen, buzz of children and teachers talking, feel of sunscreen on skin, skin gently rubbing sunscreen onto skin, and compliance with health and safety requirements.

Sense is expressed and produced in response to changes in intensity and may be expressed "as a value or emotion" (Williams, 2008, p. 6). Significance or value might be detected as what matters - in relationships, trust, playfulness, and care. Intensities might be sensed as how it feels - in physical and emotional warmth and caring, attunement, and attention focused on meeting health and safety requirements to ensure that every child has sunscreen applied before going outside. Sense is produced between the language of Mila's conversation with Tessa about her dancing and her friends, and states of affairs where trust, playfulness, and care are embodied within Tessa's happy face and Mila's calm attentiveness, in Mila's hands gently cupped around Tessa's face, and in Mila and Tessa's hands together pushing the nozzle of the sunscreen bottle.

Sense can be understood as changes in intensities in relations among sets of verb infinitives. In the vignette, verb infinitives such as to care, to take responsibility, and to comply can be understood as expressions of what is going on, not linked to particular individuals. In posthumanist terms, these verb infinitives can be understood as pre-individual and impersonal, rather than actions, thoughts, or dispositions of human individuals: "For Deleuze, ... sense and event subsist in infinitives - which are impersonal, indefinite, and do not interpellate" (St. Pierre, 2017, p. 1083, emphasis in original). Emotions become sensed as complex, dynamic, and nuanced productions of intense relations among entanglements of verb infinitives pertaining to specific situations (Williams, 2008).

\section{Sense, nonsense, and paradox: Analysing Mila's statements}

Five of Mila's statements concerning emotions in an early childhood teaching situation are analysed by mapping sense, nonsense, and paradox. An outcome of this analysis is a Deleuzian problem recurring in different ways in early childhood settings that can never be solved once and for all by best-practice prescriptions. Mila's five statements from our research conversations are:

1. Yeah, everyone else complains about how much they dislike doing it. I don't dislike doing it. I don't like how long it takes, but I don't dislike doing it because I think you make sure you have contact with all the children in the day.

2. When I first came into that room, man, they did not want sunscreen on. Like it was a really big thing for them to have sunscreen on and they kept screaming and crying.

3. I think definitely we need to respect everybody, be careful what you're doing, make sure. Because it is health and safety.

4. Every interaction I have with [Tessa], I really enjoy.

5. She's an absolute darling, she's, all the time ... The way her mind works really fascinates me and I love, I never know what she's going to say, and I always love what comes out, no matter how quirky it is, it's definitely her. It's not been influenced. 
Framing emotions in early childhood teaching within Deleuze's concept of sense: ... 28

Deleuze (1969/1990) prioritises sense over three 'traditional' linguistic dimensions of denotation, manifestation, and signification. Language can name or denote things, manifest subjects with particular desires and beliefs, and signify meanings of statements (for example, what Mila's statements 'really mean'). These dimensions tend to communicate what is familiar and taken-for-granted. Using a postqualitative cartography extends the analysis to further investigate sense's transformative potential: "A focus on sense turns us towards inventiveness, and the (potentially) unpredictable nature of experience moving forward" (Tucker, 2012, p. 782).

The specificity of the situation can be partially described as things denoted, subjects manifested, and meanings signified. Denoted things include children, teachers, inside and outside play spaces, sunscreen, centre routines and policies, children resisting or accepting having sunscreen applied, and the touch of Mila's hands smoothing sunscreen onto children's arms and faces. Mila is manifested as a caring and responsible early childhood teacher who is willing to step up for colleagues who dislike the sunscreen routine. She is responsive to children and creative, warm, and affectionate in her teaching interactions. Her statements signify that teachers are expected to respect and care for children by attending to their physical wellbeing by applying sunscreen. Teachers also care for children's emotional wellbeing by providing affection, warmth, and responsive and consistent care in enjoyable interactions.

Significations can often constitute findings in traditional qualitative research, reached by analysis by (for example) codes and themes. Such findings might confirm some familiar impressions of early childhood teaching. For Deleuze (1969/1990), such thinking follows paths of good sense, which is the sense of foreseeable progression, and common sense, which is the sense of identity and recognition, what 'everybody knows'. This cartography moves beyond denotation, manifestation, and signification to notice opportunities for something new to come about by attending to sense (concerned with significance rather than meaning). The analysis moves beyond good sense and common sense to paradox and nonsense; and then to a recurring problem that calls for creative and innovative responses in early childhood teaching.

Nonsense and paradox jolt thinking out of its usual patterns limited by common sense and good sense. They are sometimes found in the bits and pieces of data that 'don't fit', are overlooked or dismissed as irrelevant, that jar our expectations, or cause discomfort. Mila's utterance 'I'm the only person ...' in our research conversation introduces nonsense and paradox. An early childhood teacher who is usually the only one taking on the sunscreen routine, a collective, regulated responsibility of the teaching team, seems nonsensical in the landscape of early childhood teaching. It is paradoxical that Mila manages her dislike of the time the routine takes and her preference to be engaged in more enjoyable learning activities with children by taking responsibility for the routine and engaging creatively within it, thus allowing her colleagues to avoid this responsibility and engage with children in ways they prefer. When Mila's five statements are viewed alongside the paradoxical phrase 'I' $m$ the only 
person ...', sense is produced through intensities in relations among verb infinitives such as: to keep children safe, to comply with health and safety policies, to take responsibility, to support colleagues, and to care for and respect children. The emergent tensions gesture to a recurring problem in early childhood teaching of sustaining effective professional caring routines that has been actualised in a particular way in the data explored here. An everyday mundane care routine is complexified by considering 'what is going on' in terms of language, materialities, subjectivities, meanings, and sense. Teachers' professional responsibilities and actions are entangled with intensities and significance that shape their emotion expressions and experiences.

\section{A recurring Deleuzian problem}

The cartography now takes up the Deleuzian concept of problem (Deleuze, 1969/1990). A Deleuzian problem is a recurring puzzle calling for creative responses. The problem may become evident only when a (temporary and localised) solution is reached: "A problem is determined only by the singular points which express its conditions. We do not say that the problem is thereby resolved; on the contrary it is determined as a problem" (Deleuze, $1969 / 1990$, p. 56). Thinking responds creatively to emergent problems rather than following set processes to find answers to questions: "Problems are not resolvable questions but problematic knots to be retied differently" (Williams, 2008, p. 110).

A Deleuzian recurring problem immanent within the data discussed in this article is that of sustaining effective professional caring routines in face of resistance from colleagues and children. The problem is expressed in this paradoxical question: How is it possible for teachers to reconcile caring in the multiple senses of keeping safe from harm and holding warmth and affection for children, when a compulsory caring routine is disliked and resisted by both teachers and children?

Mila responds to the problem by stepping up and engaging in the routine that her colleagues dislike; by making the experience enjoyable and peaceful for her and the children; and by being playful. This is one potential response and does not solve the problem once and for all. Previously, children responded to the problem with protest and resistance and teachers responded with avoidance. Another response was enacted later, some months after this data was gathered, when a sunscreen station was provided where children apply their own sunscreen with teacher supervision.

None of these is the one right solution to the problem of sustaining effective professional caring routines. There will no doubt be other solutions when the problem recurs, in this or other early childhood settings, with these or other teaching team members and children, with this or other care routines. Teachers' emotions will be involved in all these responses to problems, in complex ways that go beyond denotation, manifestation, and signification, to the realm of sense on the frontier of language and states of affairs, where emotions are partially sensed and articulated as registrations of intensities and significance.

\section{Some implications of using Deleuzian concepts in educational research}


Theory and practice always already constitute each other in teaching and educational research, although this is not always acknowledged (Lenz Taguchi, 2010; Quinlivan, 2018). Taken-for-granted theories can be invisible, constraining possible ways researchers, teachers, children, and early childhood settings can become. An everyday, humanist approach situates emotions as discrete entities within pre-existing human individuals, and then attempts to find causes and effects that interpret what emotions do. Engaging with Deleuze's concept of sense enables a posthumanist understanding of emotions as dynamic, complex, and nuanced processes within assemblages of relationships among components that may be human and other-than-human, corporeal and incorporeal. Paradox and nonsense can point the way to something new happening immanently and to opportunities for innovation from within a situation.

In analyses using cartographies and bringing sense and associated concepts into encounter with data, something happens to understandings of how emotions and ways of becoming are shaped in early childhood teaching. Emotions can be sensed (but not always articulated) through intensity - how it feels - and significance - how it matters. When sense is understood as changes sensed in intense relations among verb infinitives that express 'what is going on' in posthumanist ways, then understandings of what emotions do in early childhood teaching can be complexified and linked to recurring problems that call for localised and innovative responses.

\section{Conclusion}

When theory and practice are understood as co-constitutive within posthumanist perspectives and an ontology of immanence, Deleuze's philosophical concepts can be mobilised to revisit taken-for-granted ideas that shape understandings of education practice. Teachers and researchers may come to understand themselves not as individuals who know, decide, and act, but emerging individuations that are always in processes of becoming. Cartographic analyses can bring Deleuzian concepts into encounter with data, exploring what else language and states of affairs can do besides telling us what we already know. By reconceptualising emotions as partially produced in intensities and significance of sense, teachers and researchers may escape some of the good sense and common sense of taken-for-granted perceptions of emotions in early childhood teaching and experiment with new, remarkable, and interesting potentialities. In specific localised early childhood teaching situations, teachers encounter recurring problems, find cracks and fractures in constraints and limits, and creatively experiment with thinking and writing that "has nothing to do with signifying. It has to do with surveying, mapping, even realms that are yet to come" (Deleuze \& Guattari, $1980 / 1987$, p. 5). Posthumanist thinking and concepts such as sense provide pedagogical opportunities for early childhood teacher education programmes and means for engagement with political forces that seek to limit understandings and expressions of emotions in early childhood teaching.

Acknowledgements: I acknowledge the guidance of my doctoral supervisors Professor Peter Roberts and Professor Kathleen Quinlivan, University of Canterbury, Christchurch, New 
Framing emotions in early childhood teaching within Deleuze's concept of sense: ... 31

Zealand, who provided feedback on drafts of this article. Sadly, Professor Quinlivan passed away in January 2020.

\section{References}

Aslanian, T. K. (2018). Remove 'care' and stir: Materialising early childhood teacher education in Norway. Journal of Education Policy, Online, 1-18.

Braidotti, R. (2019). A theoretical framework for the critical posthumanities. Theory, Culture and Society, 36(6), 31-61. https://doi.org/10.1177/0263276418771486

Colley, H. (2006). Learning to labour with feeling: Class, gender and emotion in childcare education and training. Contemporary Issues in Early Childhood, 7(1), 15-29. https://doi.org/10.2304/ciec.2006.7.1.15

Cumming, T. (2015). Early childhood educators' experiences in their work environments: Shaping (im)possible ways of being an educator? Complicity: An International Journal of Complexity and Education, 12(1), 52-66. https://doi.org/10.29173/cmplct23068

Cumming, T., \& Sumsion, J. (2014). A politics of imperceptibilities, possibilities and early childhood practice. Contemporary Issues in Early Childhood, 15(4), 368-377. https://doi.org/10.2304/ciec.2014.15.4.368

Deleuze, G. (1968/1994). Difference and repetition. London, UK: Continuum.

Deleuze, G. (1969/1990). The logic of sense (C. V. Boundas, M. Lester, \& C. J. Stivale, Trans.). London, UK: Bloomsbury Academic.

Deleuze, G., \& Guattari, F. (1980/1987). A thousand plateaus: Capitalism and schizophrenia (B. Massumi, Trans.). London, UK: Continuum.

Deleuze, G., \& Guattari, F. (1991/1994). What is philosophy? (H. Tomlinson \& G. Burchell, Trans.). New York, NY: Columbia University Press.

Hughes, J. (2009). Deleuze's Difference and Repetition: A reader's guide. London, UK: Conitnuum.

Jackson, A. Y. (2017). Thinking without method. Qualitative Inquiry, 23(9), 666-674. https://doi.org/10.1177/1077800417725355

Krejsler, J. B. (2016). Seize the opportunity to think differently! A Deleuzian approach to unleashing becomings in education. Educational Philosophy and Theory, 48(14), 14751485. https://doi.org/10.1080/00131857.2016.1163247

Lenz Taguchi, H. (2010). Going beyond the theory/practice divide in early childhood education: Introducing an intra-active pedagogy. Oxon, UK: Routledge. https://doi.org/10.4324/9780203872956

Lenz Taguchi, H. (2016). Deleuzian-Guattarian rhizomatics: Mapping the desiring forces and connections between educational practices and the neurosciences. In C. A. Taylor \& C. Hughes (Eds.), Posthuman research practices in education (pp. 37-57). New York, NY: Palgrave MacMillan. https://doi.org/10.1057/9781137453082 4 
Framing emotions in early childhood teaching within Deleuze's concept of sense: ... 32

MacLure, M. (2013a). Researching without representation? Language and materiality in postqualitative research. International Journal of Qualitative Studies in Education, 26(6), 658-667. https://doi.org/10.1080/09518398.2013.788755

MacLure, M. (2013b). The wonder of data. Cultural Studies $<=>$ Critical Methodologies, 13(4), 228-232. https://doi.org/10.1177/1532708613487863

Masny, D. (2016). Problematising qualitative research: Reading a data assemblage with rhizoanalysis. Qualitative Inquiry, 22(8), 666-675. https://doi.org/10.1177/1532708616636744

Massumi, B. (2015). Politics of affect. Cambridge, UK: Polity Press.

May, T. (2005). Gilles Deleuze: An introduction. Cambridge, UK: Cambridge University Press. https://doi.org/10.1017/CBO9781139165419

Mazzei, L. A. (2013). A voice without organs: Interviewing in posthumanist research. International Journal of Qualitative Studies in Education, 26(6), 732-740. https://doi.org/10.1080/09518398.2013.788761

Olsson, L. M. (2009). Movement and experimentation in young children's learning: Deleuze and Guattari in early childhood education. London, UK: Routledge. https://doi.org/10.4324/9780203881231

Osgood, J. (2010). Reconstructing professionalism in ECEC: The case for the 'critically reflective emotional professional'. Early Years, 30(2), 119-133. https://doi.org/10.1080/09575146.2010.490905

Osgood, J. (2012). Narratives from the nursery: Negotiating professional identities in early childhood. London, UK: Routledge.

Page, J. (2018). Characterising the principles of professional love in early childhood care and education. International Journal of Early Years Education, 26(2), 125. https://doi.org/10.1080/09669760.2018.1459508

Page, J., \& Elfer, P. (2013). The emotional complexity of attachment interactions in nursery. European Early Childhood Education Research Journal, 21(4), 553-567. https://doi.org/10.1080/1350293X.2013.766032

Quinlivan, K. (2018). Exploring contemporary issues in sexuality education with young people: Theories in practice. London, UK: Palgrave Macmillan. https://doi.org/10.1057/978-1$\underline{137-50105-9}$

Sellers, M. (2013). Young children becoming curriculum: Deleuze, Te Whāriki and curricular understandings. London, UK: Routledge. https://doi.org/10.4324/9780203111819

St. Pierre, E. A. (2017). Deleuze and Guattari's language for new empirical inquiry. Educational Philosophy and Theory, 49(11), 1080-1089. https://doi.org/10.1080/00131857.2016.1151761

St. Pierre, E. A. (2019). Post qualitative inquiry in an ontology of immanence. Qualitative Inquiry, 25(1), 3-16. https://doi.org/10.1177/1077800418772634

Tucker, I. (2012). Deleuze, sense and life: Marking the parameters of a pyschology of individuation. Theory and Psychology, 22(6), 771-785. https://doi.org/10.1177/0959354312442787

Vincent, C., \& Braun, A. (2013). Being 'fun' at work: Emotional labour, class, gender and childcare. British Educational Research Journal, 39(4), 751-768. 
Framing emotions in early childhood teaching within Deleuze's concept of sense: ... 33

Warren, A. (2019). Engaging and negotiating emotions in early childhood teaching: Towards creative critique and experimentation. (PhD Doctoral thesis), University of Canterbury, Christchurch, New Zealand. Retrieved from https://ir.canterbury.ac.nz/handle/10092/16475

Williams, J. (2008). Gilles Deleuze's Logic of Sense: A critical introduction and guide. Edinburgh, United Kingdom: Edinburgh University Press. 